\title{
Structure-properties relationship in single polymer composites based on polyamide 6 prepared by in-mold anionic polymerization
}

\author{
Nadya Dencheva $\cdot$ Zlatan Denchev · António Sérgio Pouzada · Ana Sofia Sampaio · Ana Maria Rocha
}

Received: 9 May 2013/Accepted: 18 June 2013/Published online: 29 June 2013

(C) Springer Science \& Business Media New York 2013

\begin{abstract}
Single polymer composites (SPCs) based on polyamide 6 (PA6) were prepared by in-mold activated anionic ring-opening polymerization (AAROP) of caprolactam in the presence of PA6 textile fibers. The influence of the reinforcing fibers content, their surface treatment, as well as of the temperature of AAROP upon the morphology, crystalline structure, and mechanical properties of the resulting SPCs was followed. The presence of oriented transcrystalline layer (TCL) on the surface of the reinforcing fibers was demonstrated by means of microscopy methods. Its orientation and polymorph structure were determined by synchrotron wide-angle X-ray scattering. Studies on the mechanical behavior in tension of the SPCs showed a well-expressed growth of the stress at break (70$80 \%$ ) and deformation at break (up to 150-190 \%) in composites with $15-20 \mathrm{wt} \%$ of reinforcements. The best mechanical properties were found in SPCs whose reinforcing fibers were solvent-pretreated prior to AAROP in order to remove the original finish. In these samples a stronger adhesion at the fiber/matrix interface was proved by scanning electron microscopy of cryofractured samples. This effect was related to a thinner TCL in which the $\alpha$-to- $\gamma$ polymorph transition is impeded.
\end{abstract}

N. Dencheva · Z. Denchev* . A. S. Pouzada · A. S. Sampaio I3N-Institute for Polymers and Composites, University of Minho, 4800-058 Guimarães, Portugal e-mail: denchev@dep.uminho.pt

A. M. Rocha

2C2T-Center for Textile Science and Technology, University of Minho, 4800-058 Guimarães, Portugal

\section{Introduction}

Polymer composites with thermoplastic matrices (TPC) comprising particulate or fibrous reinforcements are being used in steadily increasing number of applications due to their outstanding material performance and manufacturing flexibility [1]. Conventional TPCs reinforced by $30-50$ wt $\%$ of glass, carbon, or other mineral constituents in the form of particles, different fiber types, or structures thereof have received much academic and commercial attention in the past due to their excellent mechanical properties. Composite materials with such large amounts of mineral reinforcements, however, have displayed limited recyclability combined with high energy requirements of the respective end-of-life processes [2]. The increasing environmental concerns have led in the last decades to rigorous requirements for recycling, reuse, and design for re-integration of recycled materials in all industries where polymers make significant part of the wastes. These requirements are difficult to apply with conventional TPCs comprising high content of mineral reinforcements. The technical solutions available so far typically produce lower grade recycled materials [3] or create additional problems such as disposal of toxic solvents [4].

In conventional TPCs the organic matrix and the mineral reinforcements are very different in chemical composition, making possible only weak van der Waals type interactions across the interface between them. This reduces significantly the interfacial adhesion to the detriment of the mechanical properties [5]. In most of the cases sufficient bonding between the TPC constituents is only possible after special surface treatment of the reinforcements, which is costly and specific for each particular TPC.

Several decades ago Capiati and Porter [6] introduced the single polymer composites (SPC), in which both matrix 
and reinforcements are made from the same polymer-e.g., high-density polyethylene (HDPE). Later on the SPC concept was extended to almost all commercial polymers. Exhaustive and recent reviews on the SPC preparation, morphology, and mechanical behavior are available [1, 2]. Depending on the reinforcing component dimensions, SPC can be produced as micro- or nanocomposites. In the majority of cases SPCs based on semicrystalline polymers are prepared and studied, although amorphous-amorphous or amorphous-semicrystalline systems were also investigated [2]. The fact that in SPCs the matrix and the reinforcements are of the same material has two positive effects: it (i) increases the interfacial adhesion due to the possibility of H-bonds or even covalent bonding across the interface and (ii) turns the composite fully recyclable by reprocessing.

So far SPCs are typically prepared by melt-processing techniques. The most widely used method of this group is the hot compaction, in which polymer fibers are consolidated by applying heat and pressure. A partial melting of the outer surface of the fibers takes place thus forming the matrix. The inner part does not melt, remains highly oriented and acts as reinforcement. In such a way, SPCs of HDPE, polypropylene (PP), poly(ethylene terephthalate) (PET), and polyamide 66 (PA66) were prepared comprising very high volume fraction of reinforcing fibers, which is a clear advantage of the method [7, 8]. Its serious drawback is that the processing window does not exceed several degrees and even the slightest overheating of the fibrous material irreversibly degrades its reinforcing properties. As an attempt to resolve this problem of hot compaction, the concept of overheating of constrained fibers was developed. Under such conditions, the processing window can be increased to $26{ }^{\circ} \mathrm{C}$ for SPCs of PP [9], but for PA66 systems it still remains below $10^{\circ}$ [10].

Another consolidation method based on melt-processing toward SPCs is the film stacking [11] in which the reinforcement in the form of textile structure is sandwiched between isotropic films of the same material and the composite is produced by hot pressing. The melting of the matrix-producing film should start at a lower temperature than the reinforcement. This technique has been applied to a wide range of polymers, such as PET [12], PP [13], PE [14], and poly(lactic acid) (PLA) [15]. Bhattacharyya et al. [16] prepared polyamide 6 (PA6)-based SPCs combining hot compaction and film stacking. High-tenacity PA6 yarn as a reinforcement and PA6 film as matrix were used. Two yarn layers were sandwiched between three matrix films and subjected to compression molding at $200^{\circ} \mathrm{C}$. This method rendered PA6-based SPC with significantly increased tensile modulus and ultimate tensile strength - in the range of $100-200 \%$ as compared to the isotropic matrix film. The processing window in this case, however, remains narrow $\left(\sim 4^{\circ}\right)$ resulting in partial fiber melting. Gong and Yang [17] produced SPC based on PA6 by hot compaction of recycled fibers at $226{ }^{\circ} \mathrm{C}$ and reported maximum stresses at break in tension of $138 \mathrm{MPa}$.

Finally, the conventional melt (solution) or powder impregnation routes could also be used for preparation of TPC materials by impregnation of fiber bundles with viscous polymer resins of the same chemical composition. These techniques were used for the preparation of PE or PP SPCs, but it was recognized that they cannot provide good wetting of the reinforcements and are relatively slow and costly [18]. The main disadvantage of the melt-processing toward SPCs is the need for high processing temperatures and pressures, caused by the high melt viscosity of the matrix. Proper impregnation of the fiber at micro level proves difficult and often results in products with locally high void content. In most of the cases the processing window is much too narrow for industrial application.

A key for cost-effective preparation of TPCs with optimum impregnation of the reinforcements by the matrix material of the same chemical composition can be the significant decrease of the viscosity of the latter. This is possible in the reactive processing techniques, where the thermoplastic matrix is obtained in situ, through polymerization of low-viscosity monomers or oligomers in the presence of the reinforcements. Among the most commonly used polymerization types is the ring-opening polymerization (ROP) [19]. It is based on anionic or cationic reaction mechanisms, in which ring-shaped monomer molecules are opened and transformed into high molecular weight polymers without liberation of by-products. Thus, PA6 can be produced through activated anionic ROP (AAROP) of the inexpensive $\varepsilon$-caprolactam (ECL). The process is carried in a way that the ECL polymerization and PA6 crystallization occur simultaneously at temperatures $40-60{ }^{\circ} \mathrm{C}$ lower than the melting point of the resulting PA6 $\left(220^{\circ} \mathrm{C}\right)$. This drastically reduces the overall production cycle time and increases the energy efficiency of the process.

The AAROP of lactams to neat polyamides is thoroughly documented and well understood. Strong bases such as metal caprolactamates are most often employed as initiators of the process and imide group-containing compounds (e.g., acyl lactams)—as activators [20]. Aliphatic polyesters [21] as well as bisphenol-A polycarbonates [22] and a number of high-performance polymers have also been produced by ROP. In these cases, however, the necessary cyclic oligomers are much more expensive than the lactams, require high processing temperatures (typically above $260{ }^{\circ} \mathrm{C}$ ) and production cycles of various hours [19].

Only few studies have been reported so far on polyamide SPCs obtained by reactive processing. Gong et al. [23] prepared PA6-based SPC by AAROP of ECL in the 


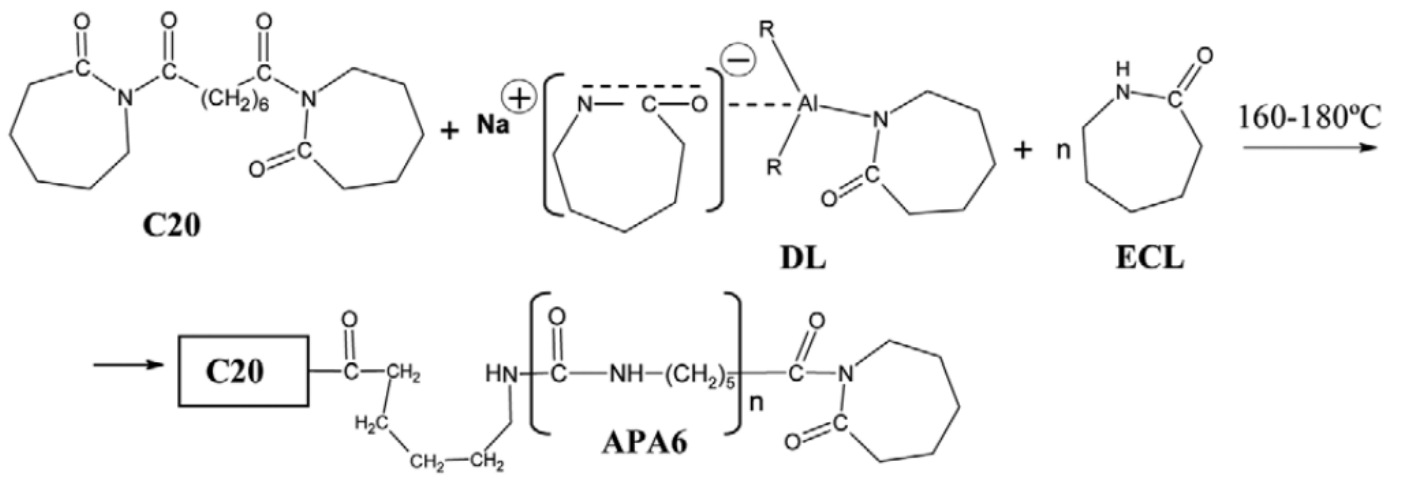

Scheme 1 Schematics of the chemical reactions and compunds in AAROP: C20 Bruggolen C20 (activator), DL dicaprolactamato-bis(2-methoxyethoxo)-aluminate, $\mathrm{R}=\mathrm{OCH}_{2} \mathrm{CH}_{2} \mathrm{OCH}_{3}$ (initiator); ECL

presence of unspecified amounts of PA6 plain weave cloth making use of a resin transfer technology (RTM). The conversion of ECL into PA6 was $93 \%$, producing a matrix with a void fraction of $<2.5 \%$ and good mechanical properties in tensile and flexural modes. Proofs of good impregnation of the fibers by the matrix material were obtained by scanning electron microscopy (SEM). Quite similar results were obtained when the combination of AAROP of ECL and RTM was used for the preparation of "all-polyamide" composites with matrices of anionic PA6 reinforced by PA66 plain weave textile structures [24]. Polarized light microscopy (PLM) studies of the all-polyamide composites showed a transcrystalline layer of PA6 upon the PA66 fiber [25].

The present work reports on the preparation of PA6-based SPC by means of in-mold AAROP of ECL in the presence of continuous PA6 textile fibers. Newly developed equipment for reactive injection molding of nylons (NYRIM) is employed. The morphology and the crystalline structure of the SPC samples is characterized by PLM, SEM, and synchrotron wide-angle X-ray scattering (WAXS). Applying a specific treatment of the WAXS data, a deeper insight on the transcrystallinity and the polymorph content in this SPC system is pursued. The relationship between the morphology, crystalline structure, and the mechanical properties in tension of PA6-based SPCs is also discussed.

\section{Experimental}

\section{Materials}

The e-caprolactam monomer (ECL) with reduced moisture content suitable for AAROP (AP-Nylon ${ }^{\circledR}$ caprolactam) was delivered by Brüggermann Chemical, Germany. Before use it was kept under vacuum for $1 \mathrm{~h}$ at $23^{\circ} \mathrm{C}$. As polymerization activator, Bruggolen $\mathrm{C}^{20 \mathrm{P}^{\circledR}}$ (C20) from e-caprolactam, APA6 anionic polyamide 6. The structure of DL is according to [29]. The structure of C20 is based on own analyses

Brüggermann Chemical, Germany was used. According to the manufacturer ${ }^{0}$ data, C20 contains $80 \mathrm{wt} \%$ of blocked diisocyanate in ECL. The supposed chemical structure of C20 is presented in Scheme 1. The initiator sodium dicaprolactamato-bis-(2-methoxyethoxo)-aluminate (80 wt\% in toluene, Dilactamate ${ }^{\circledR}$, DL, Scheme 1) was purchased from Katchem and used without further treatment.

The PA6 continuous textile fiber reinforcement monofilament with a diameter of $60 \mu \mathrm{m}$ (33/1 dtex), a round cross section, and a semi-dull treatment was obtained from ZWCH Stilon, S.A.

The acetone ("purum") was obtained from SigmaAldrich and was used without further treatment.

Samples of hydrolytic PA6 (HPA6) were produced by compression molding for $5 \mathrm{~min}$ at $240{ }^{\circ} \mathrm{C}$ and pressure of $10 \mathrm{MPa}$ of granulated medium-viscosity, general-purpose HPA6 (Durethan B30S, Lanxess, USA). They were used for comparison in the mechanical tests.

\section{Preparation of the SPC samples}

The ECL monomer was separated into two equal portions and placed into two heated flasks with magnetic stirrers. To the first of them, $1.5 \mathrm{mmol}$ of DL was added and to the second $-0.75 \mathrm{mmol}$ of C20 maintaining the temperature in the $90-110{ }^{\circ} \mathrm{C}$ range. The in-mold AAROP was performed in hydraulically actuated prototype equipment for reactive injection molding of nylons (NYRIM), whose concept and functioning were described in detail elsewhere [26]. The production cycle started by introducing the ECL/C20 and ECL/DL feeds separately into a camera preheated to $110{ }^{\circ} \mathrm{C}$ where they were mixed by jet impingement. The resulting initiated and activated molten ECL was then injected into the mold, preheated to the polymerization temperature and already containing the respective amount of PA6 continuous fibers. After elapsing the time for AAROP, the mold cooled down automatically to a preset temperature of ca. $65^{\circ} \mathrm{C}$ at a 
rate of $40 \% \mathrm{~min}$ and opened ejecting the molded composite plate $(80 \mathrm{~mm} \times 80 \mathrm{~mm} \times 3 \mathrm{~mm})$. In this study the AAROP was performed in the range of $160-170{ }^{\circ} \mathrm{C}$, setting the reaction time at $15 \mathrm{~min}$.

Table 1 summarizes the description and designations of the SPCs. The APA6 sample represents neat matrix material prepared by AAROP under the same processing conditions as the respective SPCs. APA6 and HPA6 samples were used as references in the mechanical and structural studies. Fiber concentrations in the range of $10-20 \mathrm{wt} \%$ were employed. Two sets of samples were produced for each SPC: with the as-obtained commercial PA6 textile fibers bearing their original proprietary sizing and after removing of any non-chemically bonded finish on the fiber surface by immersion in acetone for $30 \mathrm{~min}$ and subsequent drying for $2 \mathrm{~h}$ at $60^{\circ} \mathrm{C}$.

\section{Characterization techniques}

The degree of AAROP conversion was determined as a relation of the mass of the sample after and before Soxhlet extraction with methanol for $8 \mathrm{~h}$ until constant weight. Values in the range of 97-99 \% were reached. In all composites no inhibition of the polymerization process was observed.

The tensile tests were performed in an Instron model 4505 tensile testing machine. The tests were carried out at $23 \pm 2{ }^{\circ} \mathrm{C}$ with a standard load cell of $50 \mathrm{kN}$ at a constant crosshead speed of $50 \mathrm{~mm} / \mathrm{min}$. From the different composite plates prepared in the NYRIM machine, standard specimens for tensile tests according to DIN 53504-S3 were cut out, the sample thickness being of $3.0 \mathrm{~mm}$. At least five

Table 1 Sample description and designation

\begin{tabular}{llll}
\hline $\begin{array}{l}\text { AAROP } \\
\text { temperature }\left({ }^{\circ} \mathrm{C}\right)\end{array}$ & $\begin{array}{l}\text { Fibers amount } \\
(\mathrm{wt} \%)\end{array}$ & $\begin{array}{l}\text { Solution treatment } \\
\text { of fibers }\end{array}$ & $\begin{array}{l}\text { Sample } \\
\text { designation }\end{array}$ \\
\hline- & - & - & HPA6 \\
160 & - & - & APA6-160 \\
& 20 & - & $160-F-20$ \\
& 20 & + & $160-F-20 A$ \\
165 & - & - & APA6-165 \\
& 10 & - & $165-F-10$ \\
& 10 & + & $165-F-10 A$ \\
& 15 & - & $165-F-15$ \\
& 15 & + & $165-F-15 A$ \\
& 20 & - & $165-F-20$ \\
& 20 & + & $165-F-20 A$ \\
170 & - & - & APA6-170 \\
& 20 & - & $170-F-20$ \\
& 20 & + & $170-F-20 A$ \\
\hline Immersion in acetone at $23{ }^{\circ} \mathrm{C}$ for 30 min followed by drying at
\end{tabular}

specimens of each sample were studied to calculate the average and standard deviation data. The engineering stress was determined as the ratio of the tensile force to the initial cross section of the sample. The engineering strain was determined as the ratio of the sample gauge length at any time during drawing to that before drawing. The stiffness was calculated from the stress-strain curves as the secant modulus at $1 \%$ strain. In all cases samples stored for ca. 30 days at $23{ }^{\circ} \mathrm{C}$ and $65 \%$ relative humidity were tested.

The wide-angle X-ray scattering patterns (WAXS) in this study were registered at the Soft Condensed Matter Beamline (A2) of HASYLAB, Hamburg, Germany using synchrotron radiation with a wavelength fixed to $0.15 \mathrm{~nm}$. The sample-to-detector distance was set at $90 \mathrm{~mm}$, the diffraction patterns being registered by means of a MARCCD two-dimensional detector of Rayonix. The samples were studied in transmission mode with an exposure time of $25 \mathrm{~s}$. A specially designed sample holder was used allowing for controlled heating-cooling cycles in the $30-300{ }^{\circ} \mathrm{C}$ range. An Imago multichannel processor and program controller of JUMO GmbH were used to regulate the sample temperature in heating and cooling. The difference between the read-out and real temperature was found to be $3-4{ }^{\circ} \mathrm{C}$ at the heating rate of $20^{\circ} \mathrm{C} / \mathrm{min}$ applied in this study. Corrections for background scattering, irradiated volume, and beam intensity were performed for each 2D pattern. To separate the WAXS contributions of the isotropic matrix and the oriented fibers and to study the transcrystallinity, the 2D WAXS patterns were processed with POLAR 2.7.1 X-ray software [27].

The SEM study was made in a NanoSEM-200 apparatus of FEI Nova. The samples were fractured after immersion in liquid nitrogen and then coated with gold. For the transmission polarized light microscopy (PLM) study Olympus BH-2 microscope was used. The samples were prepared by microtoming normally to the fiber axis.

\section{Results and discussion}

\section{The polymerization process}

The chemistry of the activated anionic ring-opening polymerization (AAROP) of ECL is well-known since the early 1970s [20]. Scheme 1 gives an idea of the accepted reaction mechanism. AAROP in this work was initiated by the basic DL-an organo-aluminum compound that contains a stabilized caprolactamate anion. It is believed that in DL the lactam anion is with decreased nucleophility due to coordination of the $\mathrm{Al}$ atom with the lactam carbonyl oxygen leading to delocalization of the negative charge [28]. This makes DL a slower AAROP initiator as compared to the simple sodium caprolactamate. 
The activator C20 contains two preformed imide links $\mathrm{C}(\mathrm{O})-\mathrm{N}-\mathrm{C}(\mathrm{O})$, in the presence of which polymerization starts directly with the propagation reaction [29]. Having in mind the amount of activating imide groups in C20 and the initiating caprolactamate anions in DL, the mole ratio of C20:DL was always kept at 1:2. After a number of optimization experiments, the AAROP temperature was set in the $160-170{ }^{\circ} \mathrm{C}$ range, which produced the neat APA6 samples and the SPCs with 97-99 \% degree of ECL conversion within polymerization time of $15 \mathrm{~min}$.

The average viscometric molecular weight $\mathrm{M}_{\mathrm{v}}$ of the neat APA6 and the SPCs obtained at various temperatures was determined by intrinsic viscosity measurements in $97 \%$ sulfuric acid at a concentration of $0.2 \mathrm{~g} / \mathrm{L}$ with a suspended level Ubbelohde viscometer thermostatted at $25^{\circ} \mathrm{C}$. Using the Mark-Houwink equation with $\mathrm{K}=4.10^{-3}$ and $\mathrm{a}=0.7$ for PA6 [30], $\mathrm{M}_{\mathrm{v}}$ values in the range of $32,000-35,400 \mathrm{~g} / \mathrm{mol}$ were obtained. DSC measurements in heating mode at $10 \%$ min rendered single melting peak centered between 219 and $221{ }^{\circ} \mathrm{C}$ varying as a function of the AAROP temperature. These two methods confirm the preparation of high molecular weight materials.

\section{Morphological studies by microscopy}

\section{Polarized light microscopy (PLM)}

The PLM study was performed at room temperature in transmission mode with crossed polars (Fig. 1). SPCs reinforced by 10 and $20 \mathrm{wt} \%$ PA6 monofilaments were studied employing two magnifications: $10 \times$ (left column) and $100 \times$ (right column). The micrographs in lines a and $c$ are of the SPCs, in which prior to AAROP the PA6 fibers were treated with acetone (Table 1, 165-F-10A, 165-F20A). Images $b$ and $d$ were obtained with SPCs with the original sizing of the reinforcements (165-F-10, 165-F-20).

The micrographs with the lower magnification show a quite homogeneous distribution of the fibers within the in situ prepared matrix. Their cross sections are not deformed and, as expected, with no signs of melting. The bright birefringent halo around every PA6 monofilament should be attributed to an anisotropic transcrystalline layer (TCL) of APA6 matrix material crystallized upon the PA6 fiber surface during the in-mold AAROP. Formation of TCL is a frequent phenomenon in fiber-reinforced composites with semicrystalline matrices-with glass fibers [31, 32] as well as in SPCs based on isotactic PP [33]. The good lattice match between APA6 of the matrix and the PA6 fibrils seem to favor the epitaxial nucleation which initiates the formation of a TCL.

The images at higher magnification (Fig. 1, right column) visualize the spherulitic morphology of the APA6 isotropic matrix and provide a closer look on the TCL. The average thickness of the TCL "shell" in SPCs with untreated fibers (lines $b$ and $d$ ) is in the range of $3-5 \mu \mathrm{m}$, while in those with acetone-treated fibers it is slightly lower varying between 2.5 and $3.5 \mu \mathrm{m}$ (a and c). In all SPCs the average diameter of the fiber "core" remains close to $60 \mu \mathrm{m}$.

\section{Scanning electron microscopy (SEM)}

To visualize better the APA6 matrix/PA6 fiber interface, SEM studies on cryogenically fractured SPCs with $20 \mathrm{wt} \%$ of fibers were performed. Figure 2 shows the SEM images at various magnifications of the 165-F-20 composite prepared by AAROP at $165{ }^{\circ} \mathrm{C}$ without acetone pre-treatment of the reinforcing PA6 fibers. Figure 3a, b shows that the failure of this SPC is accompanied by significant load transfer to the reinforcing fibers with average diameters of ca. $60 \mu \mathrm{m}$, whereby some of them break, and other are pulled out from the matrix. As seen at higher magnifications (Fig. 3c), the textile fibers are made of bundles of axially oriented microfibrils. The interface between the matrix and the fibril that has detached from it is smooth (Fig. 3d). Figure $3 \mathrm{e}, \mathrm{f}$ displays the appearance of large cracks close to the fibril ${ }^{0}$ s surface that can be related to inhomogeneities due to the surface finishing of the monofilament. These two images also show that in a close vicinity to the fiber (i.e., 4-5 $\mu \mathrm{m}$ ) the APA6 matrix material seems to possess some orientation and above this limit is already isotropic. The thickness of this oriented layer almost coincides with that of the birefringent halo in the PLM images of the same sample (Fig. 1b, d), so it can be attributed to TCL that appears due to the solid-state crystallization of APA6 during AAROP.

Figure 3 shows the SEM micrographs of cryofractured 165-F-20A composite whose PA6 fibers were treated with acetone (desized) prior to AAROP. This treatment was expected to remove any finishing coating not being covalently bonded to the fiber surface. As seen at low magnifications (Fig. 3a-c), the sample failure occurs without pulling out of reinforcing fibrils from the matrix, i.e., no formation of holes takes place. The fibrils are well embedded within the matrix and fail typically by splitting along their axis and not by breaking at the cross section as in Fig. 2. The images at larger magnification (Fig. 3d-f) show no cracks or other defects at the fiber/matrix interface. Moreover, as seen from Fig. 3e, some entanglement between fibril and matrix material is present there. All these effects should be attributed to the good wetting of the PA6 fibril by the APA6 matrix material. As to the thickness of the TCL in these samples, values in the range of ca. 2.5-3.0 $\mu \mathrm{m}$ were determined (Fig. 3f), which is close to that found by PLM. 
Fig. 1 Polarized light microscopy images (crossed polars) of SPCs obtained by AAROP comprising 10 and $20 \mathrm{wt} \%$ of PA6 fibers at two magnifications. Left column 910, scale bar corresponds to 500 Im; Right column 9100, scale bar corresponds to $50 \mu \mathrm{m}$. Samples A and C are obtained with PA6 monofilaments treated with acetone to remove the sizing. In samples B and D the monofilaments are with their original sizing

\section{$10 \mathrm{wt} \%$ PA6 fibers}
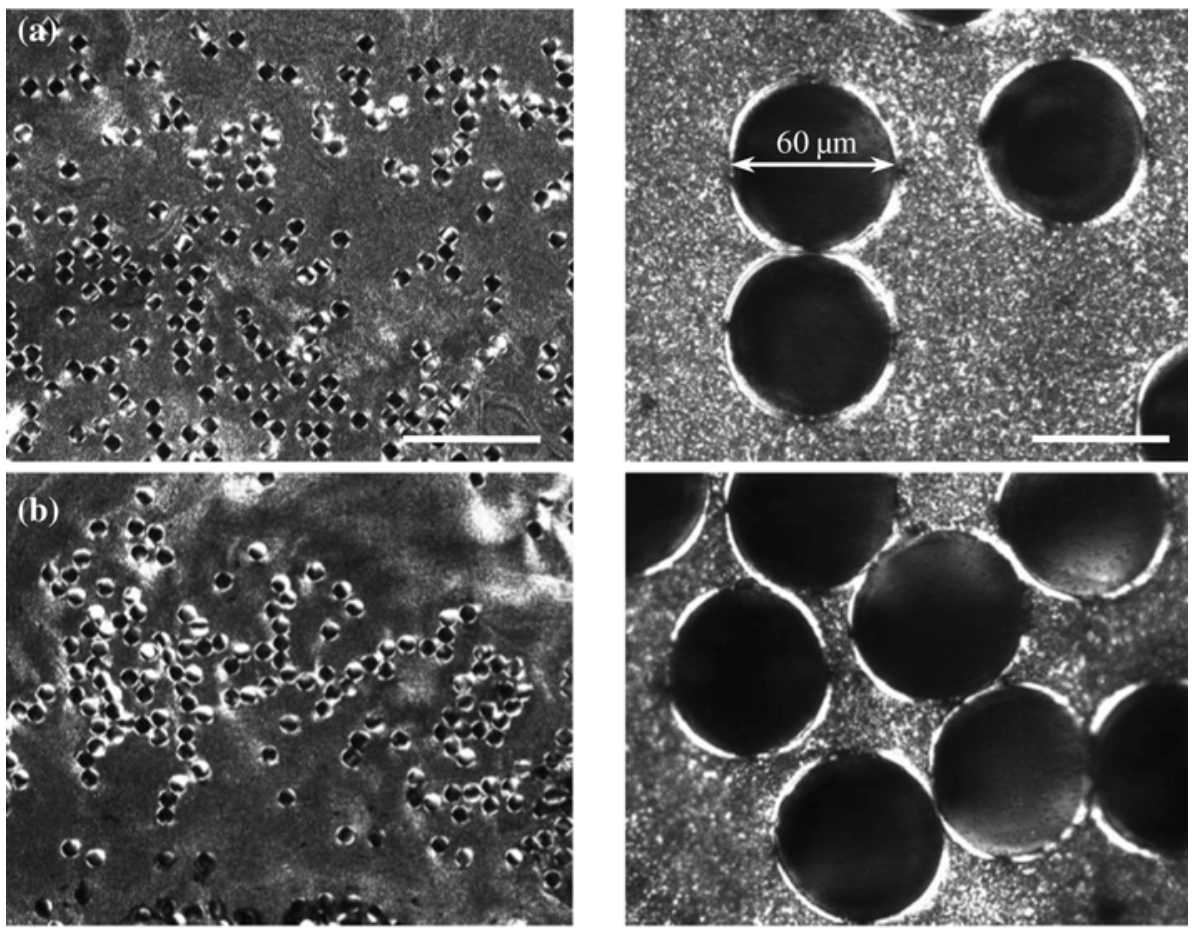

$20 \mathrm{wt} \%$ PA6 fibers
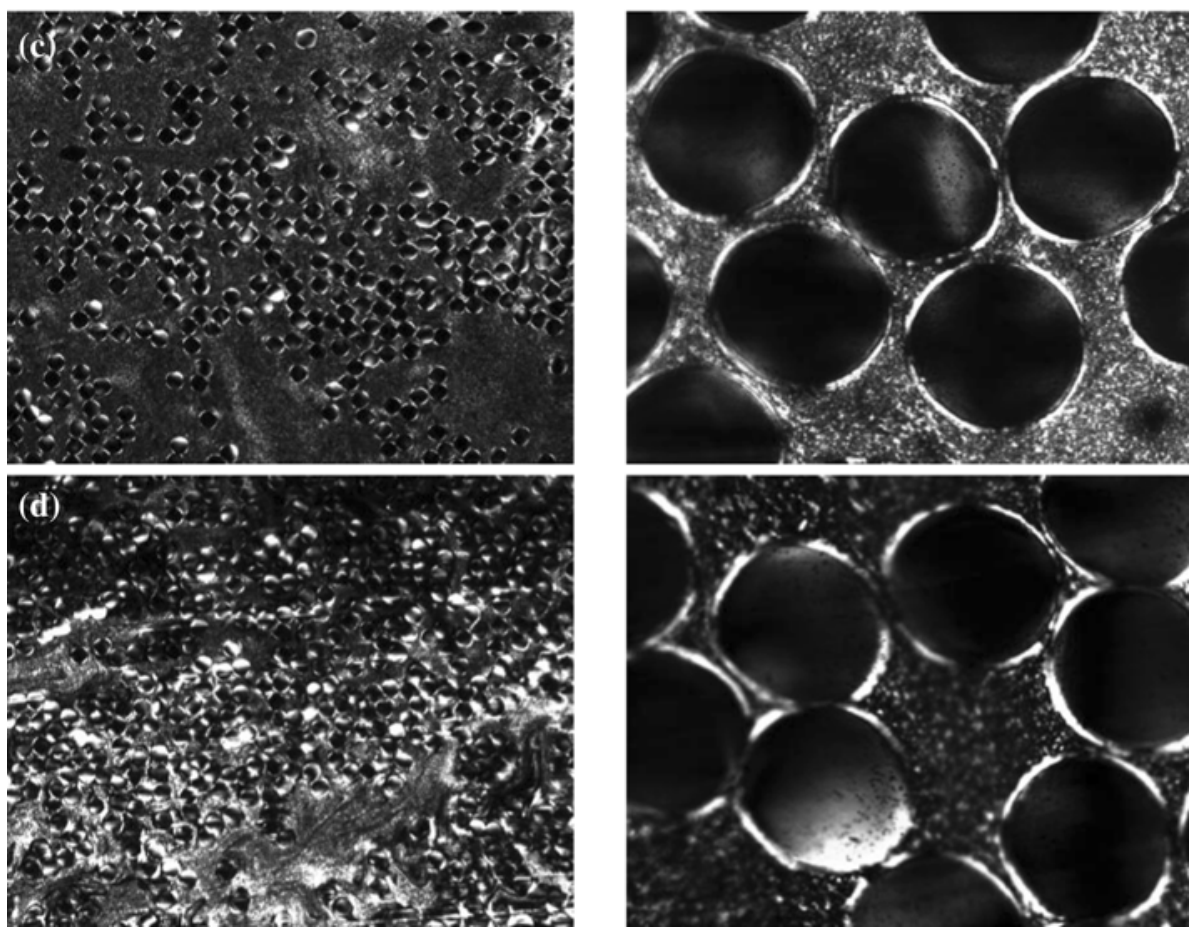

Crystalline structure and orientation in SPC by synchrotron WAXS

Previous systematic studies on transcrystallinity in conventional fiber-reinforced composites have shown that the crystalline structure of TCL (i.e., its evolution during annealing, polymorph content, orientation of the polymer chains in it, etc.) determines the nature and extent of its effect on the properties of the composite material [34, 35]. Therefore, after confirming the presence of TCL in the PA6based SPCs and the dependence of its thickness on the fibers surface treatment, its fine crystalline structure and orientation were studied. To the best of our knowledge, no such studies have been performed so far in PA6-based SPCs. 

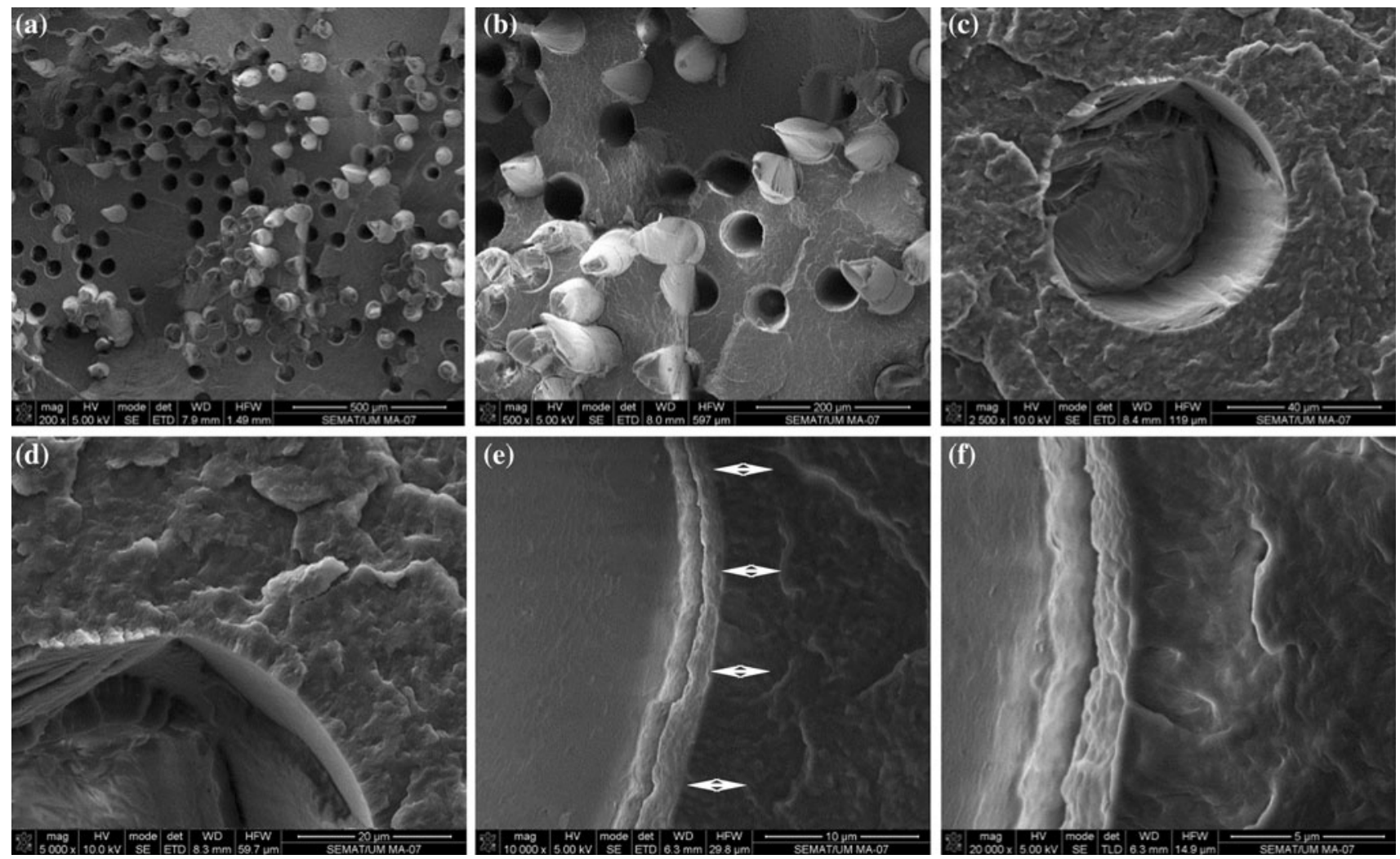

Fig. 2 SEM images at different magnifications of the SPC sample with $20 \mathrm{wt} \%$ of PA6 monofilaments without acetone treatment (Table 1, 165-F-20). Arrows in image e indicate the thickness of TCL

Synchrotron X-ray scattering techniques are frequently employed for structural investigations of transcrystallinity in in situ polymer-polymer composites [36, 37]. In a PA6based SPC such study is complicated by the fact that the fibril, the matrix, and the TCL have the same chemical composition and possess very similar crystallographic characteristics. The only significant difference will be related to the orientation of the polymer crystallites building the three SPC constituents.

Figure 4 presents the WAXS patterns of the SPC sample (as-prepared, at $30{ }^{\circ} \mathrm{C}$ and after melting at $260{ }^{\circ} \mathrm{C}$ and recrystallization) with $20 \mathrm{wt} \%$ of reinforcing fibers treated with acetone prior to AAROP (Table 1, sample 165-F20A). The visual inspection of the two-dimensional WAXS pattern of the as-prepared SPC (the inset on the left side) shows the co-existence of two isotropic Debye rings and two oriented ark-like reflections on the equator oriented parallel to the direction of the fiber axis. The Debye rings should be associated with the isotropic matrix of anionic PA6 obtained during AAROP. The equatorial reflections belong to the oriented PA6 material of the reinforcing textile fiber and to the TCL on the top of it. The linear WAXS profile of the SPC is obtained after a conventional radial integration of the 2D pattern. The two peaks at $2 \theta=20.0^{\circ}$ and $23.6^{\circ}$ are of the a-PA6 crystalline phase, which is the predominant one in the as-prepared SPC. Melting the composite at $260{ }^{\circ} \mathrm{C}$ and its recrystallization (Fig. 4, the inset on the right side) produce a completely isotropized PA6 without oriented equatorial reflections in the 2D image. The respective linear WAXS profile displays the two peaks of the $\alpha$-polymorph but with different angular positions and intensities meaning significant changes in the structure of the crystalline phase. The two linear profiles in Fig. 4 that contain the total WAXS of the SPC neither render information about the localization of these changes (i.e., fiber, TCL, or matrix), nor allow for their rigorous quantification.

A more in-depth structural characterization is possible after separation of the isotropic scattering of the APA6 matrix from the oriented scattering of the reinforcing fiber coated with TCL. The separation procedure was reported by Somani et al. [38] and Nogales and coworkers [39]. They postulated that the contributions of the randomly oriented PA6 crystals of the matrix and of all amorphous domains are directly proportional to the azimuthally independent component of the total WAXS intensity. The contribution from all oriented (with varying degree of orientation) scatterers is computed by subtracting the azimuthally independent component from the total scattered intensity. To perform the said subtraction, commercial $\mathrm{X}$-ray software was used [27]. 

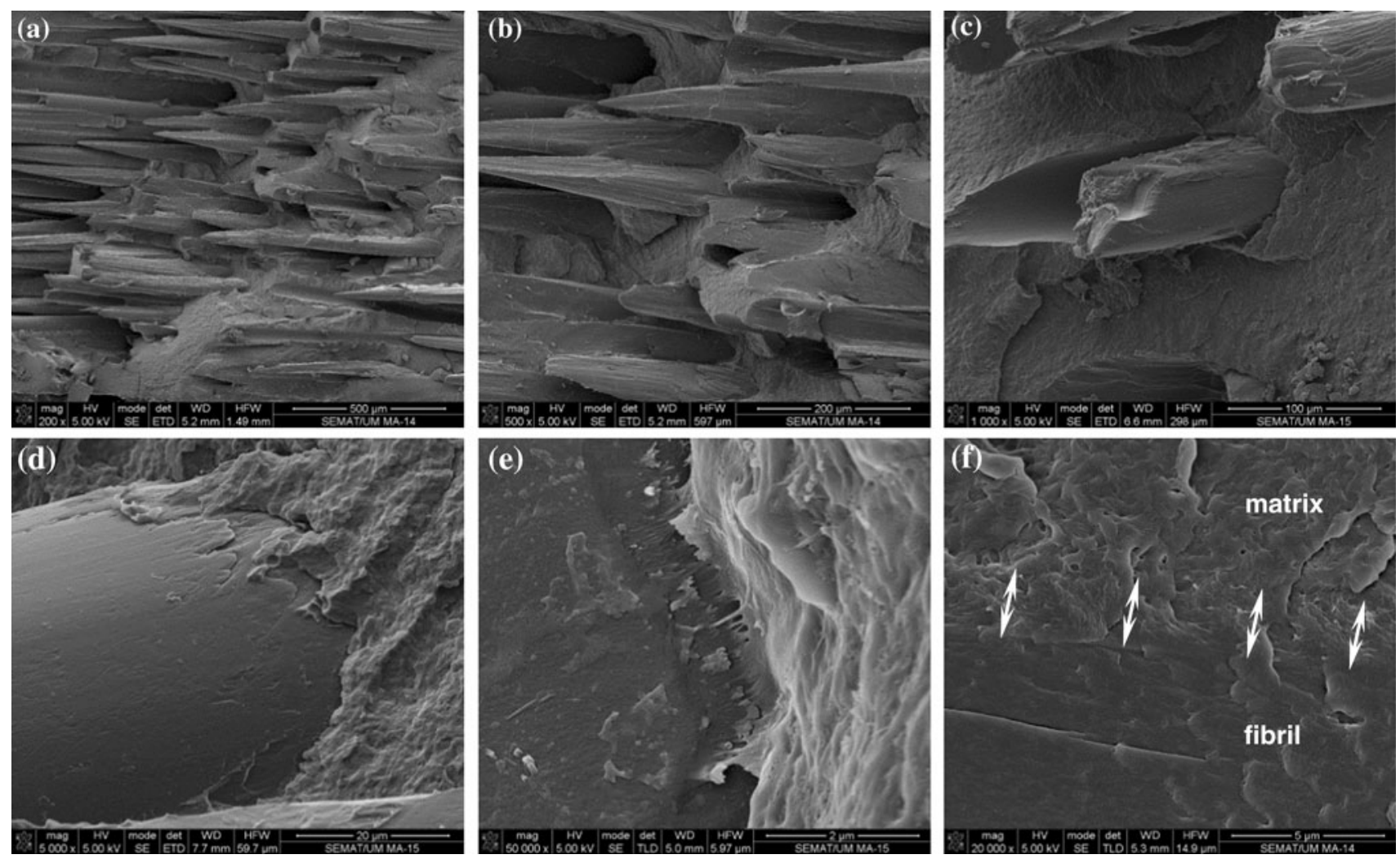

Fig. 3 SEM images at different magnifications of the SPC sample with $20 \mathrm{wt} \%$ of PA6 monofilaments with acetone treatment (Table 1, 165-F20A). Arrows in image $f$ indicate the thickness of TCL

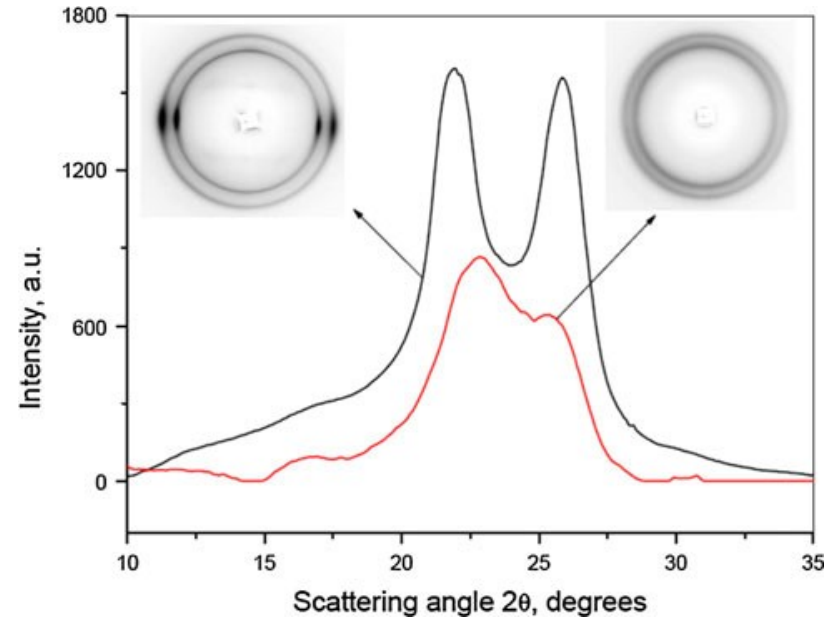

Fig. 4 WAXS patterns of 165-F-20A sample. Left inset-asprepared, at $30{ }^{\circ} \mathrm{C}$; Right inset-sample after in-beam melting at $260^{\circ} \mathrm{C}$ and cooling to $30^{\circ} \mathrm{C}$. The insets show the 2D WAXS patterns from which the linear profiles were obtained after radial integration. Fiber orientation is vertical

Figure 5 (upper line) exemplifies the WAXS intensity separation for the 165-F20A sample displaying the starting 2D WAXS (left), the computed isotropic part of the scattered intensity (center), and the resulting 2D WAXS image of the oriented part after subtraction (right). The bottom line in the same figure shows the 3D representation of the total WAXS and of its oriented component in which the vertical z-axis displays the intensity. The orientation (i.e., the azimuthal dependence) of the two strongest PA6reflections in both the total and oriented WAXS is clearly observed. The internal reflection belongs to the 200 crystalline plane of monoclinic $\alpha$-PA6 crystals and the external - to the 002/202 plane of the same polymorph [40].

To extract further structural information, the separated 2D WAXS images of the oriented and isotropic WAXS components shown in Fig. 5 were subjected to radial integration and the resulting linear profiles were deconvoluted by peak-fitting (Fig. 6). Four crystalline peaks were necessary to fit the profile of the oriented WAXS (Fig. 6a) meaning that two types of oriented monoclinic $\alpha$-PA6 crystallites with similar but distinguishable d-spacing coexist in this SPC sample. The more intense reflections at $2 \theta=21.6^{\circ}$ and $25.7^{\circ}$ (line-patterned peaks) were attributed to the oriented PA6 material of the reinforcing fiber. The dark-shaded less intense peaks at $2 \theta=20.3^{\circ}$ and $23.8^{\circ}$ were supposed to originate from the TCL on the top of the fiber. Since no off-equatorial reflections are found in the oriented WAXS in Fig. 5, the direction of chain orientation in TCL most probably coincides with that in the oriented textile- 


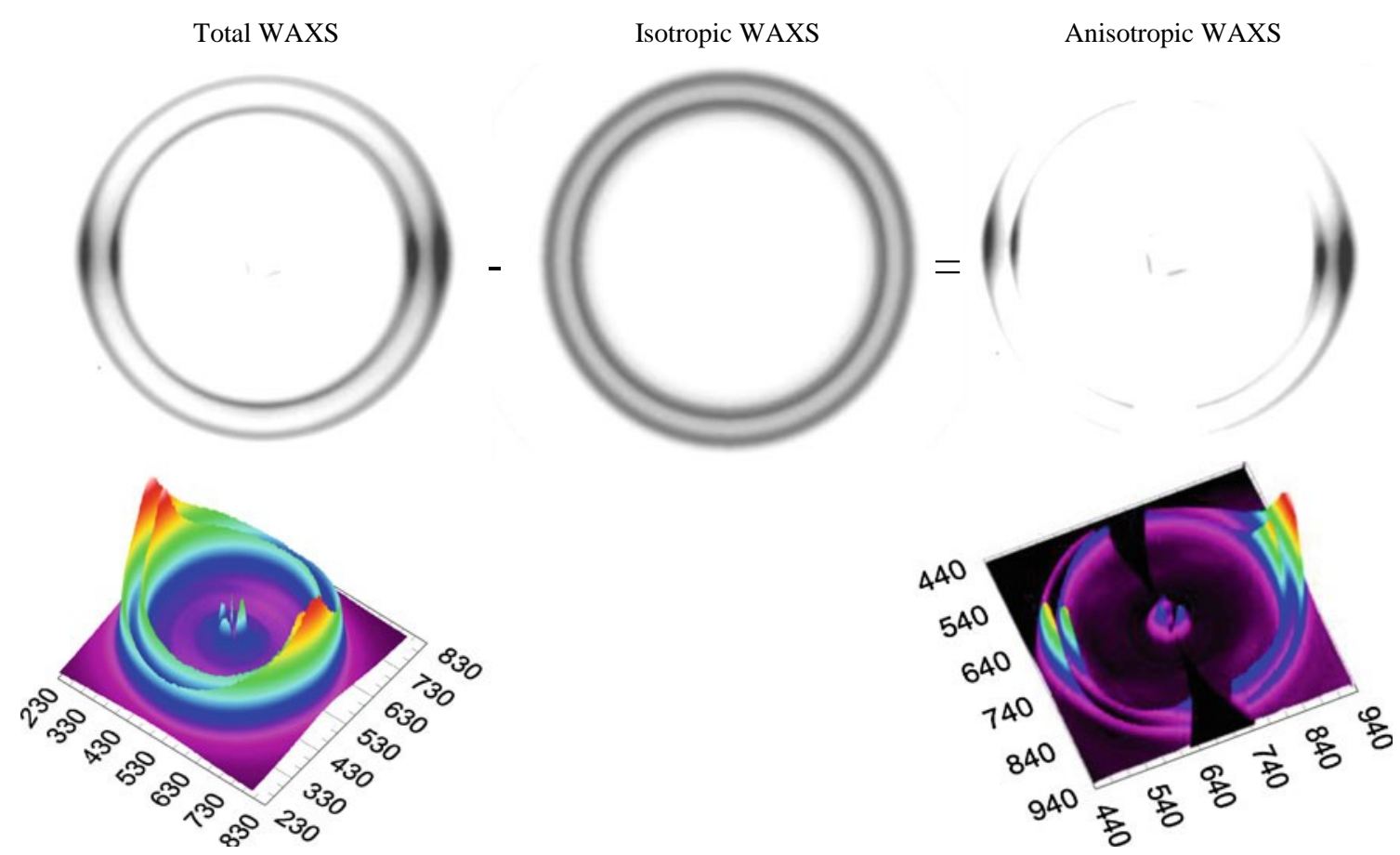

Fig. 5 Upper line Separation of the total WAXS into isotropic and anisotropic parts characterizing the non-oriented APA6 matrix and oriented PA6 fiber with the TCL. The reinforcing monofilaments are

aligned vertically. Bottom line 3D image of the total WAXS and the anisotropic WAXS, presenting the scattered intensity of the z-axis

reinforcing fiber. No peaks for $\gamma$-PA6 phase were found in the oriented WAXS of the as-prepared sample irradiated at $30{ }^{\circ} \mathrm{C}$. As stated above, the oriented WAXS should be considered $100 \%$ crystalline hence no peak for diffuse scattering of amorphous phase was considered in this case.

The peak-fitting of isotropic WAXS of the same sample (Fig. 6b) revealed the crystalline structure of the APA6 matrix with clear peaks for pseudo-hexagonal $\gamma$-polymorph $\left(2 \theta=12.4^{\circ}, 23.4^{\circ}\right.$, and $24.4^{\circ}$ of the 020,001 , and 200 crystalline planes, respectively), as well as for monoclinic $\alpha$-PA6 at $22.0^{\circ}$ and $26.3^{\circ}$. All these reflections should be ascribed to the isotropic APA6 matrix material. Interestingly, no good fit could be obtained without introduction of two more peaks at $2 \theta=22.5$ and $25.3^{\circ}$. Having in mind their $2 \theta$ positions and intensities, they are attributable to a fraction of randomly oriented $\alpha$-PA6 crystals within the reinforcing fiber. Evidently, the latter should comprise a non-oriented core and oriented shell, covered by a TCL. The overall degree of crystallinity of the iso-WAXS fraction $\mathrm{X}_{\mathrm{c}}=45 \%$ was determined after subtracting the contributions of the two diffuse scattering peaks of the amorphous phase (dashed lines in Fig. 6a).

Separations of the WAXS patterns into oriented and isotropic fractions and their deconvolution were performed analogously for samples 165-F20A, 165-F20, and APA6165 after annealing at different temperatures. The oriented WAXS of the two SPCs was studied at $30{ }^{\circ} \mathrm{C}$ (the asprepared composites), at $170{ }^{\circ} \mathrm{C}$, as well as after $5 \mathrm{~min}$

in-beam heating at $200{ }^{\circ} \mathrm{C}$ and recrystallization (pattern taken at $30{ }^{\circ} \mathrm{C}$ ) (Table 2). The polymorph content and the $\mathrm{a} / \mathrm{c}$ relation were determined. The patterns of the isofractions were studied similarly at the same three temperatures (Table 3), together with the pattern at $30{ }^{\circ} \mathrm{C}$ of the samples isotropized by melting at $260{ }^{\circ} \mathrm{C}$ (Table 4). In Tables 3 and 4 the parameters of the neat APA6-165 sample were included to enable comparison.

Analyzing the structural information in Tables 2, 3, and 4 allows conclusions about the crystalline structure of the PA6-based SPCs under investigation and its dependence on the surface treatment of the reinforcing fibers and the thermal annealing of the composite. Table 2 shows that the oriented WAXS of the composite samples without and with solvent pretreatment of the reinforcing fibers contain only a-form crystallites, whereby in the latter case the intensity of the peaks related to the TCL is significantly lower. Supposing that the $\alpha_{\mathrm{TCL}}$ and $\alpha_{\mathrm{F}}$ peak intensities correspond to the volumes of the oriented TLC and reinforcing fiber material, respectively, it can be concluded that the thickness of the TCL in the as-prepared SPC reinforced by untreated PA6 fibers will be larger than in the case of removal of the fiber finish. This is exactly what was determined by both PLM and SEM studies (Figs. 1, 2, 3). Annealing the oriented fraction of the SPC material to $170{ }^{\circ} \mathrm{C}$ causes intensive $\alpha$-to-c-form transformation (Brill transition). Table 2 shows that it occurs to a different extent, depending on the solvent treatment of the fiber. 
Without it, both TCL and fiber material contribute to the formation of the $\gamma$-polymorph, reaching $\alpha / \gamma$ ratio of 1.7 . With acetone treatment, the amount of the $\alpha$-PA6 in TCL remains unchanged, the $\gamma$-fraction originating only from the oriented fiber material. Apparently, in this SPC where a direct contact between TCL and the reinforcing fiber
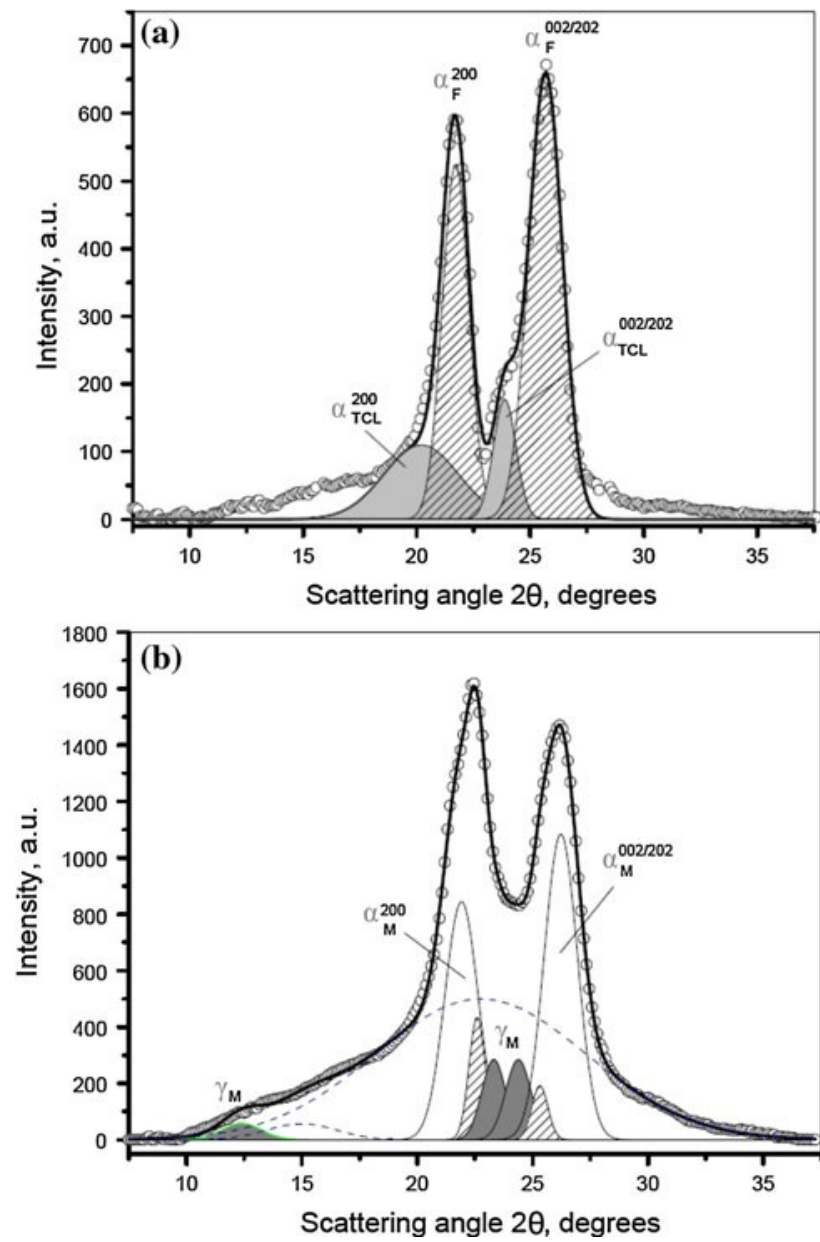

Fig. 6 WAXS profile deconvolution by peak-fitting for: a oriented part of the WAXS scattering; b isotropic part of the WAXS scattering. Sample: SPC with $20 \mathrm{wt} \%$ of monofilaments treated with acetone (165-F-20A). Indices F, TCL, and M denote fiber, transcrystalline layer, and matrix, respectively. For more details see the text surface can be supposed, $\alpha$-to $\gamma$-phase transition is hampered. Heating to $200{ }^{\circ} \mathrm{C}$ and recrystallization at $30{ }^{\circ} \mathrm{C}$ in this sample lead to disappearance of the oriented $\gamma$-polymorph. In the SPC with no solvent pre-treatment of the fibers (i.e., TCL grows on the top of the fiber finish), the same treatment produces a significant amount of $\gamma$-fraction originating from both fiber and TCL.

Table 3 displays the evolution of the polymorph content and the crystallinity indices in the isotropic APA6 matrix in samples $165-\mathrm{F} 20$ and $165-20 \mathrm{~A}$ at three different temperatures. Both samples display quite similar values, all the differences being within the frames of the experimental error (5-6\%). Notably, the a/c ratio in the matrices of the initial as-prepared SPCs at $30{ }^{\circ} \mathrm{C}$ is $2.5-3.0$ times larger than that at $170{ }^{\circ} \mathrm{C}$ and after in-beam annealing at $200{ }^{\circ} \mathrm{C}$. In the neat APA6 these two values are almost the same. Moreover, the $\alpha / \gamma$ ratio at $170{ }^{\circ} \mathrm{C}$ in the SPCs is more than three times larger than in the $\gamma$-phase-rich neat matrix. Evidently, the matrix APA6 in the composites (i.e., in the presence of oriented reinforcing fibers) is less susceptible to $\alpha$-to- $\gamma$ transition than the neat APA6 material.

Table 4 shows the evolution of the polymorph content in the two SPCs after isotropization by melting at $260{ }^{\circ} \mathrm{C}$ and subsequent cooling to $30^{\circ} \mathrm{C}$, as well as in the respective neat APA6 with the same thermal treatment. The neat matrix displays $\alpha / \gamma$ ratio of 3.4, i.e., the same as in the asprepared sample (Table 3). Melting and recrystallization of the SPC in which the fiber finish was removed leads to a relative increase of the $\gamma$-polymorph as compared to the other SPC with untreated fibers.

Summarizing, modification of the surface treatment of the reinforcing monofilaments has a clear effect on the polymorph content in both TCL and matrix in the as-prepared SPCs. It also changes the completeness of the Brill transition upon annealing or recrystallization at temperatures in the $170-260{ }^{\circ} \mathrm{C}$ range.

\section{Mechanical properties of SPC materials}

To characterize the tensile behavior of composites very frequently the stress-strain curves and the information

Table 2 Polymorph content in the oriented WAXS fraction for the SPS samples with $20 \mathrm{wt} \%$ of PA6 fibers (without and with acetone treatment) at three different temperatures

\begin{tabular}{|c|c|c|c|c|c|c|c|c|c|c|c|c|c|c|c|}
\hline \multirow[t]{2}{*}{ Fiber wt\% } & \multicolumn{5}{|c|}{ As-prepared, at $30{ }^{\circ} \mathrm{C}$} & \multicolumn{5}{|l|}{ At $170{ }^{\circ} \mathrm{C}$} & \multicolumn{5}{|c|}{ At 30 after $200^{\circ} \mathrm{C}$} \\
\hline & $\alpha_{\mathrm{TCL}}(\%)$ & $\alpha_{\mathrm{F}}(\%)$ & $\alpha_{\mathrm{T}}(\%)$ & $\gamma(\%)$ & $\alpha / \gamma$ & $\alpha_{\mathrm{TCL}}(\%)$ & $\alpha_{\mathrm{F}}(\%)$ & $\alpha_{\mathrm{T}}(\%)$ & $\gamma_{\mathrm{T}}(\%)$ & $\alpha / \gamma$ & $\alpha_{\mathrm{TCL}}(\%)$ & $\alpha_{F}(\%)$ & $\alpha_{\mathrm{T}}(\%)$ & $\gamma_{\mathrm{T}}(\%)$ & $\alpha / \gamma$ \\
\hline 20 & 32.8 & 67.2 & 100 & 0.0 & - & 17.2 & 46.0 & 63.2 & 36.8 & 1.7 & 25.2 & 48.1 & 77.3 & 26.7 & 2.8 \\
\hline $20^{\mathrm{a}}$ & 23.0 & 77.0 & 100 & 0.0 & - & 23.1 & 57.6 & 80.7 & 19.3 & 4.2 & 30.5 & 69.5 & 100 & 0.0 & - \\
\hline
\end{tabular}

TCL transcrystalline layer, $\mathrm{F}$ fiber, $\mathrm{T}$ total amount of the respective crystalline fraction

a Acetone treatment 
Table 3 Polymorph content and total crystallinity $\mathrm{X}_{\mathrm{c}}$ calculated from the non-oriented WAXS fraction for the SPC samples with 20 wt\% of PA6 fibers (without and with acetone treatment) and of the neat APA6 matrix at three different temperatures

\begin{tabular}{|c|c|c|c|c|c|c|c|c|c|c|c|c|}
\hline \multirow[t]{2}{*}{ Fiber (wt\%) } & \multicolumn{4}{|c|}{ As-prepared, at $30{ }^{\circ} \mathrm{C}$} & \multicolumn{4}{|c|}{ at $170{ }^{\circ} \mathrm{C}$} & \multicolumn{4}{|c|}{ At 30 after $200{ }^{\circ} \mathrm{C}$} \\
\hline & $\mathrm{X}_{\mathrm{c}}(\%)$ & $\alpha(\%)$ & $\gamma(\%)$ & $\alpha / \gamma$ & $\mathrm{X}_{\mathrm{c}}(\%)$ & $\alpha(\%)$ & $\gamma(\%)$ & $\alpha / \gamma$ & $\mathrm{X}_{\mathrm{c}}(\%)$ & $\alpha(\%)$ & $\gamma(\%)$ & $\alpha / \gamma$ \\
\hline & \multicolumn{12}{|c|}{ Isotropic WAXS fraction } \\
\hline 20 & 38.6 & 32.1 & 6.5 & 5.0 & 47.2 & 30.3 & 16.9 & 1.8 & 42.5 & 24.4 & 18.1 & 1.4 \\
\hline \multirow[t]{2}{*}{$20^{\mathrm{a}}$} & 45.2 & 37.1 & 8.1 & 4.6 & 38.1 & 23.6 & 14.5 & 1.6 & 44.7 & 29.5 & 15.2 & 1.9 \\
\hline & \multicolumn{12}{|c|}{ Neat PA6 matrix } \\
\hline- & 51.8 & 39.4 & 12.4 & 3.2 & 45.3 & 15.6 & 29.7 & 0.5 & 53.1 & 37.7 & 15.4 & 2.5 \\
\hline
\end{tabular}

a Acetone treatment

Table 4 Polymorph content and total crystallinity $\mathrm{X}_{\mathrm{c}}$ calculated after isotropization at $260{ }^{\circ} \mathrm{C}$ and recrystallization of the SPC samples with $20 \mathrm{wt} \%$ of PA6 fibers (without and with acetone treatment) and of the respective neat APA6 matrix

\begin{tabular}{llccc}
\hline Fiber (wt\%) & \multicolumn{4}{l}{ At 30 after $260{ }^{\circ} \mathrm{C}$ (after melting and recrystallization) } \\
\cline { 2 - 5 } & $\mathrm{X}_{\mathrm{c}}(\%)$ & $\alpha(\%)$ & $\gamma(\%)$ & $\alpha / \gamma$ \\
\hline 20 & 38.9 & 24.1 & 14.8 & 1.6 \\
$20^{\mathrm{a}}$ & 42.6 & 13.6 & 29.0 & 0.5 \\
& \multicolumn{2}{l}{ Neat PA6 matrix } & & \\
- & 49.7 & 38.4 & 11.3 & 3.4 \\
\hline
\end{tabular}

a Acetone treatment

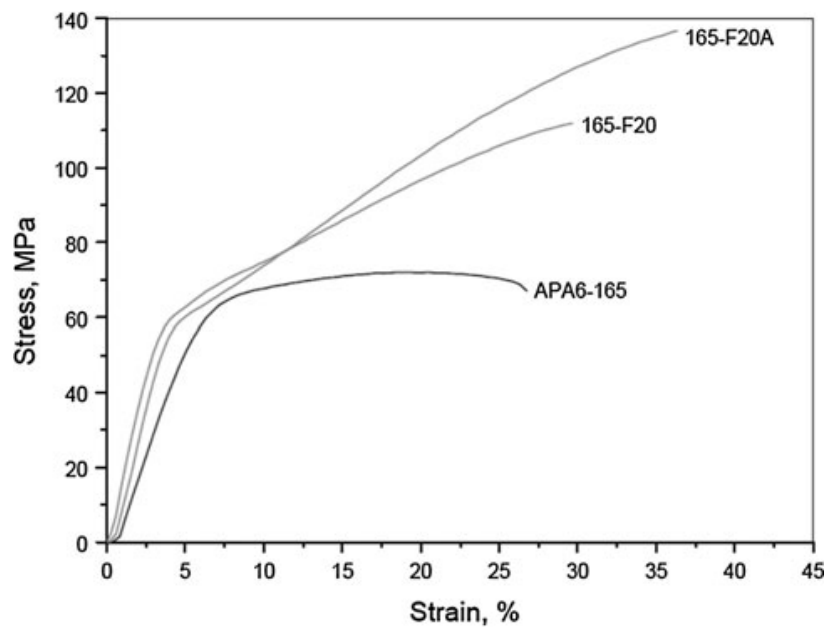

Fig. 7 Comparison of the stress-strain curves in tension of representative SPC materials and the respective neat matrix material

extracted from them are used. Figure 7 shows two representative curves of the 165-20F and 165-20FA SPCs, as well as of the neat APA6-165. As expected, the curve of the neat matrix material displays clear elastic and plastic regions. Very similar stress-strain curves were obtained previously with compression-molded isotropic plates of neat HPA6 annealed at $160{ }^{\circ} \mathrm{C}$ [41]. In the stress-strain curves of the SPCs, instead of yielding as in APA6, a well-expressed strain-hardening process starting at deformations of 3-5\%
Table 5 Mechanical properties in tensile mode (DIN 53504-S3) PA6-based SPCs obtained at different AAROP temperatures and containing various amounts of reinforcements without or with prior solvent treatment of the fibers

\begin{tabular}{llrl}
\hline $\begin{array}{l}\text { Sample } \\
\text { designation }\end{array}$ & $\begin{array}{l}\text { Young } \\
\mathrm{E}(\mathrm{GPa})\end{array}$ & \multicolumn{1}{c}{$\begin{array}{l}\text { Stress at break } \\
\left.\sigma_{\mathrm{br}} / \mathrm{MPa}\right)\end{array}$} & $\begin{array}{l}\text { Strain at break } \\
\varepsilon_{\mathrm{br}}(\%)\end{array}$ \\
\hline HPA6 & $1.01 \pm 0.04$ & $47.0 \pm 4.0$ & $24.0 \pm 3.0$ \\
APA6-160 & $1.57 \pm 0.08$ & $67.7 \pm 3.4$ & $17.7 \pm 5.1$ \\
160-F-20 & $1.56 \pm 0.06$ & $111.3 \pm 7.2$ & $25.8 \pm 6.6$ \\
160-F20A & $1.61 \pm 0.08$ & $123.5 \pm 7.0$ & $37.7 \pm 7.5$ \\
APA6-165 & $1.61 \pm 0.06$ & $70.2 \pm 3.7$ & $13.0 \pm 8.1$ \\
165-F10 & $1.73 \pm 0.05$ & $80.0 \pm 5.2$ & $20.2 \pm 6.1$ \\
165-F10A & $1.69 \pm 0.06$ & $84.8 \pm 4.2$ & $18.8 \pm 4.4$ \\
165-F15 & $1.57 \pm 0.07$ & $70.2 \pm 3.9$ & $26.6 \pm 5.1$ \\
165-F15A & $1.71 \pm 0.06$ & $98.7 \pm 6.2$ & $17.7 \pm 5.2$ \\
165-F20 & $1.68 \pm 0.06$ & $101.4 \pm 7.0$ & $24.4 \pm 4.3$ \\
165-F20A & $1.74 \pm 0.08$ & $122.5 \pm 9.0$ & $38.1 \pm 7.0$ \\
APA6-170 & $1.47 \pm 0.06$ & $61.7 \pm 3.0$ & $19.9 \pm 8.2$ \\
170-F20 & $1.71 \pm 0.05$ & $90.0 \pm 3.0$ & $27.5 \pm 6.1$ \\
170-F20A & $1.73 \pm 0.06$ & $96.0 \pm 2.5$ & $33.7 \pm 4.6$
\end{tabular}

Note: Samples are conditioned for ca. 20 days at $23{ }^{\circ} \mathrm{C}$ and $65 \%$ relative humidity before the mechanical test

is observed. The relatively short elastic regions are with increased slopes as compared to the neat matrix material suggesting higher Young's modulus (E values). Interestingly, the strain-hardening in the SPC with solvent-pretreated reinforcing fibers is larger and contributes to a bigger ultimate strength $\left(\sigma_{\text {br }}\right)$ and strain at break values $\left(\varepsilon_{\text {br }}\right)$.

Table 5 displays the evolution of $\mathrm{E}, \sigma_{\mathrm{br}}$, and $\varepsilon_{\mathrm{br}}$ in all SPCs as a function of the fiber reinforcement amount (without and with solvent pretreatment) and of the AAROP temperature, always comparing to the respective neat matrices. Data for HPA6 compression-molded from granules and annealed at $160{ }^{\circ} \mathrm{C}$ are also represented to enable comparison. In comparison to HPA6, the neat matrix APA6 anionically produced at $160{ }^{\circ} \mathrm{C}$ has lower $\varepsilon_{\mathrm{br}}$, higher $\mathrm{E}$ and $\sigma_{\mathrm{br}}$; the relative improvement in the latter two cases being 55 and $44 \%$, respectively. Provided that all samples of this 
study are mechanically tested after prolonged storing at $23{ }^{\circ} \mathrm{C}$ and $65 \%$ relative humidity, they are expected to be conditioned. This explains why the $\mathrm{E}$ values for neat HPA6 and APA6 are relatively low, in the range of 1.0-1.6 GPa. Testing of conditioned samples was accepted since it has a better relation to the long-term exploitation of polyamides. The $\mathrm{E}$ values for dried samples can be twice as high but rapidly deteriorate at environmental exposure.

Table 5 shows that the $\mathrm{E}$ values of the SPCs obtained by AAROP at three different temperatures are statistically identical to those of neat APA6 prepared under the same conditions. They seem to depend neither on the amount of reinforcing fibers, nor on their solvent pretreatment. This was to be expected, having in mind that the volume fractions of the PA6-reinforcing fibers are relatively low and that their E-moduli without prolonged annealing in the $160-200{ }^{\circ} \mathrm{C}$ are only slightly larger than that of the matrix-1.78 GPa against 1.01 GPa [41].

The SPCs with 15-20 wt\% reinforcements show a clear relative improvement in $\mathbf{r}_{\mathrm{br}}$ of $70-80 \%$ as compared to the respective neat matrix, the upper limit of the interval being related to the SPC with solvent-pretreated reinforcements. Interestingly, in the latter SPCs along with the growth of $\sigma_{b r}$, the deformation at break $\varepsilon_{b r}$ also increases in a statistically significant way. Apparently, the mechanical behavior in tension of the SPCs is directly related to the amount of PA6 fibers and their finishing, the optimal AAROP temperature being between 160 and $165^{\circ} \mathrm{C}$.

\section{Structure-properties relationship in PA6-based SPCs by $A A R O P$}

The critical analysis of the mechanical data in conjunction to the structure and morphology results from microscopy and WAXS helps identify three factors that can influence to different extent the mechanical properties of the SPCs studied. The SEM data show that the removal of the fiber finish (desizing) results in the absence of weak boundary layers at the fiber/matrix interface. This is probably the most important factor leading to better adhesion, better load transfer from the matrix to the reinforcing fibers, and, therefore, to higher stresses at break for all SPCs with desized fibers. Second, as seen from the PLM and SEM results, the TCL in the SPCs with such fibers is thinner and in direct contact with the PA6 fiber. This may cause more intense physical and chemical interactions i.e., H-bond formation, chain entanglements, or even direct chemical bonds at the TCL/fiber interface created during the simultaneous polymerization and crystallization of the matrix. Such explanation agrees with the mechanical data in Table 5 where the SPCs reinforced with desized fibers display superior $\sigma_{\mathrm{br}}$ values compared to SPC with the same content of non-treated reinforcements.
The effect of the above two factors is expected to be decisive for the better mechanical properties of the SPCs with solvent-treated fibers. However, the influence of the crystalline structure of the fiber, matrix, and TCL (mostly crystallinity index and polymorph content) should be discussed as well. As shown by many authors [40-44], the thermodynamically more stable $\alpha$-phase is monoclinic, formed by anti-parallel polymer chains, wherein amide and $\mathrm{CH}_{2}$ groups lay within the same plane. H-bond formation occurs between adjacent anti-parallel chains, thus forming sheets of H-bonded chains. The antiparallel arrangement of macromolecular chains of the $\alpha$-polymorph can occur in the presence of chain folding [40] and is typical for isotropic PA6. The $\gamma$-phase is considered to have pseudo-orthorhombic [42, 43] or pseudo-hexagonal lattice [44] built up of parallel polymer chains. To enable H-bond formation in this case, the amide linkages should twist by $\sim 60^{\circ}$ out of the plane of the molecular sheets. This is expected to result in inferior hydrogen bonding (and probably lower hardness and stiffness) in the $\gamma$-phase as compared to the $\alpha$-polymorph [40]. The more ductile $\gamma$-polymorph is typical of PA6-oriented samples obtained by cold drawing. Phase transitions in oriented and isotropic PA6 can be caused by appropriate thermal treatment or application of external strain. Most frequently the less stable $\gamma$-PA6 is transformed into the more stable $\alpha$-PA6 [41].

From the data of the oriented WAXS summarized in Table 2 it can be seen that at $30{ }^{\circ} \mathrm{C}$ both TCL and reinforcing fiber comprise only $\alpha$-PA6 phase irrespective of the solvent treatment. This fact is rather unexpected as far as the PA6 fiber is concerned but it can be explained with an intensive $\gamma$-to- $\alpha$ transition during the AAROP that takes place at $165^{\circ} \mathrm{C}$. Supposing that the intensities of $\alpha_{\mathrm{TCL}}$ and $\alpha_{F}$ peaks for $165-F-20$ and 165-F-20A samples (Fig. 6; Table 2) are proportional to the respective crystalline volumes and that the fiber volume fraction is constant, it can be concluded that the TCL in sample 165-F-20 is thicker than that in 165-F-20A composite. This conclusion is in good agreement with the microscopy results.

The temperature-induced $\alpha$-to- $\gamma$ transition is typical for oriented PA6 when annealing is kept in the $120-180{ }^{\circ} \mathrm{C}$ range [41]. The $\alpha / \gamma$ ratio at $170{ }^{\circ} \mathrm{C}$ in Table 2 suggests that this transition is more difficult in the SPC with solventtreated fibers. This effect is an indirect proof for the existence of physical and chemical interactions between the desized fiber and TCL leading to the aforementioned phase transition constrains.

The isotropic WAXS at $30{ }^{\circ} \mathrm{C}$ (Table 3) originating from the matrix material of the two SPCs and from neat APA6 show that the composite matrices are richer in $\alpha$ polymorph but show lower crystallinity indices. The direct relation of this structural observation to the mechanical properties (i.e., $\mathrm{E}, \varepsilon_{\mathrm{br}}$, and $\sigma_{\mathrm{br}}$ ) is not straightforward. It 
seems, however, that the polymorph content in the isotropic fractions of the two SPCs is quite similar and cannot determine the differences in the mechanical properties. Nevertheless, it may be suggested that any treatment that could increase the amount of the $\alpha$-PA6 phase in the matrix, fiber reinforcement, or TCL of SPC can potentially increase its E-modulus and $\sigma_{\mathrm{br}}$ values. As to the $\varepsilon_{\mathrm{br}}$ values, the results in Table 5 and the static WAXS measurements are not conclusive enough. Additional simultaneous synchrotron X-ray/straining experiments could shed more light on the evolution of the matrix nanostructure of SPC as a function of strain.

The WAXS data in Fig. 4 and Table 4 show that heating of SPCs for short times at $260{ }^{\circ} \mathrm{C}$ does really remove the orientation of the fiber reinforcements but the polymorph content of the resulting recycled PA6 is quite different as compared to that of the APA6. This observation can be relevant to the establishing of the optimal conditions for SPC recycling by melt-processing techniques.

\section{Summary}

SPCs with PA6 fibers-reinforced PA6 matrix were successfully prepared by in-mold anionic polymerization of caprolactam using newly developed prototype equipment. Judging from the PLM and SEM studies, the synthetic route ensures homogeneous distribution of the reinforcing PA6 fibers without any disruption of their form due to melting. Formation of TCL at the fiber/matrix interface was clearly demonstrated. The TCL thickness and the fracture behavior of the SPCs were found to depend on the surface treatment of the reinforcing fibers, whereby those without finish displayed superior adhesion to the matrix material. A WAXS study of the crystalline structure of three composite constituents (i.e., matrix, fiber, and TCL) was performed as a function of the monofilament solvent pretreatment and the crystallization/recrystallization temperatures. A dependence of the polymorph content of the TCL and the underlying oriented PA6 of the reinforcing fiber was found on the surface treatment of the reinforcements. Their desizing results in thinner TCL in which the $\alpha$-to- $\gamma$ polymorph transition is impeded. The initial mechanical tests in tension performed with samples with relatively low amount of reinforcements in the 15-20 wt\% showed that the SPCs produced at optimal AAROP temperatures using solvent-pretreated reinforcements outperform the neat APA6 matrix by $70-80 \%$ in terms of the stress at break showing also to a significant growth of the deformation at break-up to $190 \%$. Further improvement of the SPC mechanical behavior would require a larger amount of fiber reinforcements and optimization of their surface, mechanical, and thermal treatment.
Acknowledgements The authors gratefully acknowledge the financial support of HASYLAB at DESY (Grant Number II-07011EC) and of the Strategic Project LA 25-2011-2012 financed by Fundação para a Ciênica e Tecnologia (FCT)—Portugal. N. D. is grateful to the FCT for supporting her research by the post-doctoral award SFRH/BPD/45252/2008, co-financed by QREN-POPH program of EU.

\section{The final publication is available at:}

http://link.springer.com/article/10.1007/s10853-013-7546-8

\section{References}

1. Matabola KP, de Vries AR, Moolman FS, Luyt AS (2009) J Mater Sci 2009(44):6213. doi:10.1007/s10853-009-3792-1

2. Fakirov S (2013) Macromol Mater Eng 298:9

3. Banik K, Abraham TN, Karger-Kocsis J (2007) Macromol Mater Eng 292:1280

4. Poulakis JG, Varelidis PC, Papaspyrides CD (1997) Adv Polym Technol 16:313

5. Raghavendran VK, Drzal LT (2002) J Adhes 78:895

6. Capiati NJ, Porter RS (1975) J Mater Sci 10:1671. doi: 10.1007/BF00554928

7. Ward IM, Hine PJ (2004) Polymer 45:1413

8. Hine PJ, Ward IM (2005) In: Michler GH, Baltá-Calleja FJ (eds) Mechanical properties of polymers based on nanostructure and morphology. CRC, Boca Raton, p 683

9. Barkoula NM, Peijs T, Schimanski T, Loos J (2005) Polym Compos 26:114

10. Hine PJ, Ward IM (2006) J Appl Polym Sci 101:991

11. Barany T, Karger-Kocsis A, Czigany $T$ (2006) Polym Adv Technol 17:818

12. Hine PJ, Ey RH, Ward IM (2008) Compos Sci Technol 68:1413

13. Abraham TN, Wanjale SD, Barany T, Karger-Kocsis J (2009) Compos A 40:662

14. Jenkins MJ, Hine PJ, Hay JN, Ward IM (2006) J Appl Polym Sci 99:2789

15. Li RH, Yao DG (2008) J Appl Polym Sci 107:2909

16. Bhattacharyya D, Maitrot P, Fakirov S (2009) Express Polym Lett 3:525

17. Gong Y, Yang G (2010) J Appl Polym Sci 118:3357

18. Lacroix FV, Lu H, Schulte K (1999) Compos A 30:369

19. van Rijswijk K, Bersee HEN (2007) Compos A 38:666

20. Roda J (2009) In: Dubois P, Coulembier OJ-M, Raquez J-M (eds) Handbook of ring-opening polymerization. Wiley-VCH, Wencheim, p 165

21. Brunelle DJ, Bradt JE, Serth-Guzzo J, Takekoshi T, Evans TL, Pearce E, Wilson P (1998) Macromolecules 31:4782

22. Brunelle DJ, Krabbenhoft HO, Bonauto DK (1993) Polym Preprints USA 34:73

23. Gong Y, Liu A, Yang G (2010) Compos A 41:1006

24. Gong Y, Yang G (2010) J Mater Sci 45:5237. doi:10.1007/ s10853-010-4565-6

25. Wu B, Gong Y, Yang G (2011) J Mater Sci 46:5184. doi: 10.1007/s10853-011-5452-5

26. Dencheva N, Pouzada AS, Brito AM, Oliveira FM, Denchev Z, Costa PF, Semiautomatic laboratory equipment for reactive injection molding, preprints of the 5th polymers and mold innovation conference (PMI-2012), Gent, September 2012

27. POLAR, version 2.7.3; Copyright (c) 1997-2008 by Stonybrook Technology and Applied Research, Inc, USA

28. Veith CA, Cohen RE (1991) Makromol Chem Macromol Symp 42/43:241

29. Dan F, Vasiliu-Oprea C (1998) Colloid Polym Sci 276:483

30. Mateva R, Delev O (1995) Polym J 27:499

31. Isada H, Bussi P (1991) Macromolecules 24:3569 
32. Stern T, Wachtel E, Marom GJ (1997) J Polym Sci 35:2429

33. Loos J, Schimanski T, Hofman J, Peijs T, Lemstra PJ (2001) Polymer 42:3827

34. Quan H, Li Z-M, Yang M-B, Huang R (2005) Comp Sci Technol 65:999

35. Nuriel H, Klein N, Marom G (1999) Compos Sci Technol 59:1685

36. Dencheva N, Oliveira MJ, Carneiro OS, Pouzada AS, Denchev Z (2010) J Appl Polym Sci 115:2918

37. Dencheva N, Denchev Z, Oliveira MJ, Funari SS (2010) Macromolecules 43:4715
38. Somani RH, Hsiao BS, Nogales A, Srinivas S, Tsou AH, Sics I, Baltá-Calleja FJ, Ezquerra TA (2000) Macromolecules 33:9385

39. Nogales A, Hsiao BS, Somani RH, Srinivas S, Tsou AH, BaltaCalleja FJ, Ezquerra TA (2001) Polymer 42:5247

40. Samon JM, Schultz JM, Hsiao BS (2000) Polymer 41:2169

41. Dencheva N, Denchev Z, Oliveira MJ, Funari SS (2007) J Appl Polym Sci 103:2242

42. Varlot LK, Reynaud E, Kloppfer MH, Vigier G, Varlet J (2001) J Polym Sci Part B 39:1360

43. Lin L, Argon AS (1992) Macromolecules 25:4011

44. Fornes TD, Paul DR (2003) Polymer 44:3945 